Editorials

\title{
Differential attainment in medical education and training
}

BMJ 2020; 368 doi: https://doi.org/10.1136/bmj.m339 (Published 11 February 2020)Cite this as: BMJ 2020;368:m339

Katherine Woolf, associate professor in medical education

\section{A systemic problem requiring openness and strong leadership}

Doctors from ethnic minority backgrounds face disadvantage throughout their careers, as highlighted by this collection of articles in The BMJ (bmj.com/racism-in-medicine). It is therefore unsurprising that despite being selected for high academic achievement, medical students from ethnic minority groups end up performing worse on average than their white counterparts during education and training. This phenomenon is called "differential attainment."

Differential attainment appears at medical school and persists after qualification. As a result, ethnic minority graduates of UK medical schools have worse outcomes during recruitment for foundation, specialty training, and consultant posts; are more likely to fail examinations; and progress more slowly through training even when exam failure has been accounted for.1

Differential attainment is a difference in average group performance, not individual performance. Many ethnic minority students and doctors excel, and many white doctors perform poorly. The finding, however, that ethnic minority medical graduates in the UK have 2.5 times higher odds of failing exams compared with their white peers 2 is hugely important for doctors and the health service.

Tackling inequalities in medical education and training is important to ensure patients can benefit from an ethnically diverse medical workforce.s Providers of education and training in the UK have legal and regulatory obligations to monitor and tackle inequalities.4 Knowing differential attainment exists is not enough; we must act to eliminate it.

\section{Challenging beliefs}

When differential attainment was first reported in 1995, it was assumed that biased examiners were marking down ethnic minority candidates.5 This belief still prevails despite strong evidence that the effects are similar in machine marked multiple choice examinations 6 and despite research showing a lack of bias in examiner marking.7

Another common belief is that differential attainment results from learner deficits among ethnic minority candidates. However, differences remain after controlling for pre-university attainment and socioeconomic status, 8 own and parents' first language, motivation for being a doctor, study habits, living arrangements (home or away), and personality.6 
It is important to ensure that examinations are unbiased (and there is little evidence on the fairness or otherwise of workplace based assessments and recruitment), and it is also unhelpful to assume everyone arrives at medical school with equivalent experiences and resources, but focusing solely on trying to "fix" examinations or student deficits risks stigmatising learners and misallocating resources.

Instead, the evidence points to improving the learning experience for ethnic minority students. Learning is social, and interactions between students, teachers, and peers critically affect outcomes, 9 yet these are patterned by ethnicity.10 An international review found that minority medical students "experienced less supportive social and less positive learning environments [and] were subject to discrimination and racial harassment."11

Tackling this institutional problem requires openness and strong leadership. Leaders should make it clear that differential attainment is a systemic problem that affects everyone and not just a problem for ethnic minority students, or one caused by learner deficits. They should inform their approach with local evidence about the outcomes and experiences of ethnic minority learners but guard against inaction if data are lacking because of small numbers of ethnic minority students or staff.

Students and trainees learn best from seniors who are interested in them, believe in them, and give them opportunities to develop.12 Sponsorship is an important predictor of career success.13 As teachers we should reflect on who we give additional support and opportunities to, ensure ethnic minority learners stretch themselves, and create opportunities for those from different ethnic groups to learn together since this combats prejudice.14 Teachers and supervisors need support if they are to fulfil the vital role they have in tackling differential attainment. Fair hiring and promotion processes may help improve the under-representation of clinical academics, teachers, and supervisors from ethnic minority groups.

\section{Celebrate diversity}

Forty per cent of UK medical students are from ethnic minority groups, 15 yet teachers are often ill equipped to discuss ethnicity, and students are taught about ethnic differences as a problem to manage.16 We need doctors to teach about diversity in an integrated and sensitive manner and to create environments in which diversity is understood and celebrated. Making curriculums more inclusive is a good start, but we also need trained staff and more senior staff from diverse backgrounds.

Discrimination against NHS staff predicts poorer patient satisfaction,17 yet research by The $B M J$ found evidence that discrimination at medical school typically goes unreported.15 Campaigns on recognising and dealing with discrimination and "microaggressions" are increasing, and the BMA has just launched a charter for medical students on tackling harassment.15 Improving systems to tackle unprofessional behaviours must also continue.

We don't yet have strong evidence supporting specific interventions to reduce differential attainment. But rapid progress can be made through the steps outlined above, along with funding for the development and rigorous evaluation of initiatives, systematic synthesis and sharing of evidence, and implementation of effective strategies. Elimination of all differential attainment is the ultimate goal. 


\section{Acknowledgments}

I thank Libby Cooper and Mala Rao for feedback on a draft.

\section{Footnotes}

Competing interests: I have read and understood BMJ policy on declaration of interests and have no relevant interests to declare.

Provenance and peer review: Commissioned; not externally peer reviewed.

\section{References}

1. $\triangleleft$ General Medical Council. The state of medical education and practice in the UK.General Medical Council, 2015. Google Scholar

2. $\triangleleft$ Woolf K, Potts HWW, McManus IC . Ethnicity and academic performance in UK trained doctors and medical students: systematic review and metaanalysis. BMJ2011;342:d901. doi:10.1136/bmj.d901 pmid:21385802 Abstract/FREE Full TextGoogle Scholar

3. $\triangleleft$ Saha S, Guiton G, Wimmers PF, Wilkerson L. Student body racial and ethnic composition and diversity-related outcomes in US medical schools. JAMA2008;300:1135-

45. doi:10.1001/jama.300.10.1135 pmid:18780842 CrossRefPubMedWeb of ScienceGoogle Scholar

4. + General Medical Council Promoting excellence - equality and diversity considerations. GMC, 2016. Google Scholar

5. $\triangleleft$ Dillner L. Manchester tackles failure rate of Asian students. BMJ1995;310:209. doi:10.1136/bmj.310.6974.209 pmid:7866116 FREE Full TextGoogle $\underline{\text { Scholar }}$

6. + Woolf K, McManus IC, Potts HWW, Dacre J. The mediators of minority ethnic underperformance in final medical school examinations. Br J Educ Psychol2013;83:13559. doi:10.1111/j.2044-8279.2011.02060.x pmid:23369179 CrossRefPubMedGoogle Scholar

7. $\longleftarrow$ Yeates P, Woolf K, Benbow E, Davies B, Boohan M, Eva K. A randomised trial of the influence of racial stereotype bias on examiners' scores, feedback and recollections in undergraduate clinical exams. BMC Med2017;15:179. doi:10.1186/s12916-017-09430 pmid:29065875 CrossRefPubMedGoogle Scholar

8. $\backsim$ Broecke S, Nicholls T. Ethnicity and degree attainment (research report RW92). Department for Education and Skills, 2007. Google Scholar

9. $\longleftarrow$ Schneider M, Preckel F. Variables associated with achievement in higher education: A systematic review of meta-analyses. Psychol Bull2017;143:565-

600. doi:10.1037/bul0000098 pmid:28333495CrossRefPubMedGoogle Scholar

10. + Woolf K, Potts HWW, Patel S, McManus IC . The hidden medical school: a longitudinal study of how social networks form, and how they relate to academic performance. Med Teach2012;34:577-86. doi:10.3109/0142159X.2012.669082 pmid:22746963 CrossRefPubMedGoogle Scholar 
11. $\dashv$ Orom H, Semalulu T, Underwood W 3rd. . The social and learning environments experienced by underrepresented minority medical students: a narrative review. Acad Med2013;88:176577. doi:10.1097/ACM.0b013e3182a7a3af pmid:24072111 CrossRefPubMedGoogle Scholar

12. + Woolf K, Rich A, Viney R, Needleman S, Griffin A. Perceived causes of differential attainment in UK postgraduate medical training: a national qualitative study. BMJ Open2016;6:e013429. doi:10.1136/bmjopen-2016-013429 pmid:27888178 Abstract/FREE Full TextGoogle Scholar

13. $\triangleleft \mathrm{Ng}$ TWH, Eby LT, Sorensen KL, Feldman DC . Predictors of objective and subjective career success: a meta-analysis. Person Psychol2005;58:367-408.doi:10.1111/j.17446570.2005.00515.x. $\underline{\text { CrossRefGoogle Scholar }}$

14. $\triangleleft$ Pettigrew TF, Tropp LR . A meta-analytic test of intergroup contact theory. J Pers Soc Psychol2006;90:751-83. doi:10.1037/0022-3514.90.5.751 pmid:16737372 CrossRefPubMedWeb of ScienceGoogle Scholar

15. $\nmid$ Kmietowicz Z . Professor, we have a problem. BMJ2020;368:m420. doi:10.1136/bmj.m420. CrossRefGoogle Scholar

16. «Karani R, Varpio L, May W, et al Commentary: racism and bias in health professions education: how educators, faculty developers, and researchers can make a difference. Acad Med2017;92(11S):S1-6. doi:10.1097/ACM.0000000000001928 pmid:29065016 CrossRefPubMedGoogle Scholar

17. $\longleftrightarrow$ Dawson J . Links between NHS staff experience and patient satisfaction: Analysis of surveys from 2014 and 2015. Workforce Race Equality Standard (WRES).NHS England, 2018. Google Scholar 